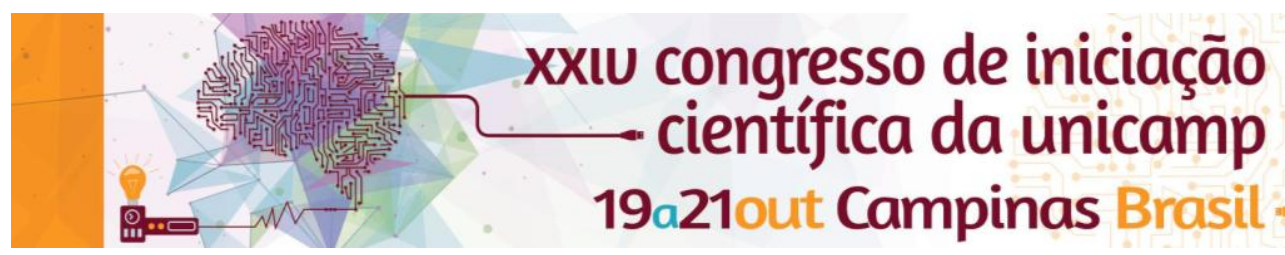

\title{
Ação dos peptídeos hormonais PYY e TFF2 sobre a via de sinalização da leptina em hipotálamo de camundongos Swiss.
}

\section{Rafael Marostica, Thiago Matos Ferreira de Araújo, Andressa Coope dos Santos, Joseane Morari, Erika Anne de Freitas Robles Roman, Lício Augusto Velloso.}

\section{Resumo}

Os mecanismos de controle da ingestão alimentar e gasto energético envolvem uma série de interações entre intestino, sistema nervoso central (SNC) e tecido adiposo. Os peptídeos intestinais $\mathrm{Y}_{3-36}\left(\mathrm{PYY}_{3-36}\right)$ e Trefoil fator family 2 (Tff2) são exemplos de moléculas relacionadas à homeostase energética. Estudos demonstraram a capacidade dos peptídeos em questão agir sobre populações neurais do núcleo arqueado, como NPY/AgRP e POMC/CART, de forma a modular a ingestão alimentar e o gasto energético. Neste contexto o objetivo deste trabalho foi o de explorar a ação do $P Y Y_{3-36}$ e Tff2 em células hipotalâmicas de camundongos, sob o estímulo da leptina.

\section{Palavras-chave}

TFF2, CXCR4, Leptina, Homeostase energética.

\section{Introdução}

A obesidade é definida como um acúmulo anormal e excessivo de gordura. Indivíduos que sofrem desta condição apresentam um desequilíbrio na regulação central do consumo e gasto de energia ${ }^{1}$. Hormônios e peptídeos, tais como insulina e leptina, atuam sobre neurônios hipotalâmicos controlando a ingestão alimentar e o gasto energético ${ }^{2}$. Além destes peptídeos é sabido atualmente que há uma interação entre intestino, sistema nervoso central e tecido adiposo, mediada por outros peptídeos, tais como: (CCK), glucagon-like peptide (GLP-1), peptídeo YY(PYY) e o Trefoil Factor Family 2 (Tff2) ${ }^{3}$. Desta forma o objetivo deste trabalho foi investigar: i) a ação de peptídeos gastrointestinais, $P Y Y_{3-36}$ e Tff2 em linhagem celular hipotalâmica de camundongos (mHypoA- 2/29 CLU189), sob o estímulo com leptina; ii) a modulação da expressão do neuropeptídeo AgRP, sob o estímulo com leptina; iii) Verificar a expressão dos Tff2 e seu receptor CXCr4 em hipotálamo de camundongos Swiss submetidos a uma dieta rica em gordura.

\section{Resultados e Discussão}

Figura 1A - Expressão do receptor CXCR4, em neurônios -mHypoA-2/29-CLU189 - (Leptina 50nM - 3 horas).
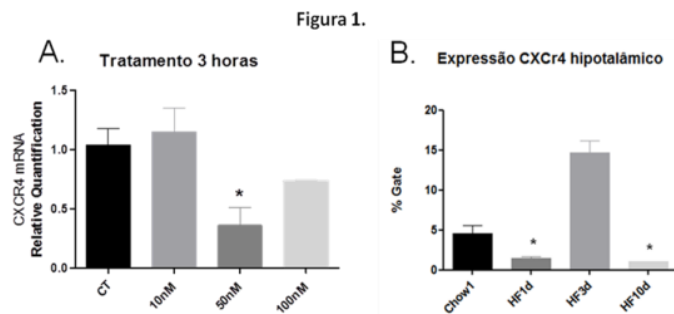

Figura 1. Expressão de $\mathrm{CXCr} 4$ em cultura celular e hipotálamo.

Figura 1B - Expressão de CXCr4, por citometria de fluxo, no hipotálamo de camundongos alimentados com dieta rica em gordura.
Fig 2A-C - Expressão de Tff2, CXCr4 e AgRP em hipotálamo de camundongos em jejum indicando um caráter orexigênico da via Tff2/CXCr4.

Figura 2.

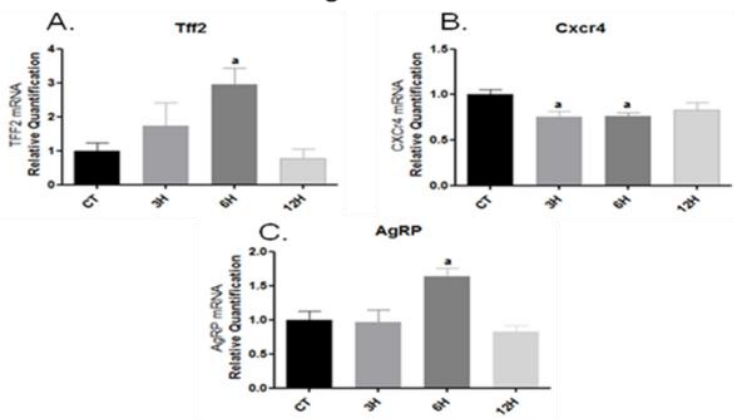

Figura 2. Expressão de Tff2, CXCr4 e AgRP hipotalâmicos.

\section{Conclusões}

A leptina modula negativamente a expressão de CXCR4 em linhagem mHypoA-2/29 -CLU189. A dieta rica em gordura (HFD), por 03 dias, modula positivamente a expressão de CXCR4 em células hipotalâmicas de camunongos Swiss. O jejum induz a um aumento na expressão hipotalâmica de Tff2 e AgRP, bem como uma diminuição na expressão de CXCr4. Dessa forma, concluímos que o Tff2 atua em paralelo ao AgRP, em estado de jejum, no sentido de incrementar o estímulo orexigênico controlando assim a homeostase energética.

\section{Agradecimentos}

FAPESP (CEPID/OCRC), CAPES, CNPq, FCM/UNICAMP.

${ }^{1}$ WORLD HEALTH ORGANIZATION, Global Health Observatory (GHO) data, Overweight and obesity, 2015

2 SCHWARTZ, M.; PORTE, JR. D. Diabetes, obesity, and the brain. Science, 2005. 375-379p.

${ }^{3}$ ASARIAN, L.; BÄCHLER, T. Neuroendocrine control of satiation. Hormons Molecular Biology Clinical Investigation, 2014. 163-92p. 